\title{
Viabilidade para Criação de uma Fábrica de Calçados em Missão Velha-CE
}

\author{
Manoel Barros Duarte ${ }^{1}$; Manoel Leal Costa Neto ${ }^{2}$
}

\begin{abstract}
Resumo: O ramo calçadista vem crescendo exponencialmente na região do Cariri, com ênfase na cidade de Juazeiro do Norte-CE, sendo esta considerada um polo calçadista, surgindo oportunidades nas cidades circundantes. $\mathrm{O}$ presente trabalho tem como objetivo analisar a viabilidade da implantação de uma empresa calçadista na cidade de Missão velha CE. Para tal utilizou-se de metodologia quantitativa, exploratória e descritiva. Foi utilizado o GoogleForms e questionários. Tendo a opinião de 251 pessoas, foi observada a aceitação do público e motivação na hora de escolher um calçado. Como resultado observou-se a viabilidade na implantação do negócio, com o retorno aproximadamente em 12 messes trazendo benefícios para a cidade de Missão Velha-CE, bem como geração de renda.
\end{abstract}

Palavras-Chave: Calçados. Empreendedorismo. Plano de negócio.

\section{Feasibility for the Creation of a Footwear Factory in the City of Missão Velha, State of Ceará}

\begin{abstract}
The footwear branch has been growing exponentially in the region of Cariri, with emphasis in the city of Juazeiro do Norte-CE, being considered a footwear pole, appearing opportunities in the surrounding cities. The present work has the objective of analyzing the viability of the implantation of a footwear company in the city of old Mission CE. For that, a quantitative, exploratory and descriptive methodology was used. It was used GoogleForms and questionnaires. Having the opinion of 251 people, was observed the acceptance of the public and motivation when choosing a footwear. As a result, it was observed the feasibility in the implementation of the business, with the return in approximately 12 months bringing benefits to the city of Missão Velha-CE as well as income generation.
\end{abstract}

keywords: Footwear. Entrepreneurship. Business plan.

\section{Introdução}

Segundo os dados do Serviço brasileiro de apoio às micro e pequenas empresas (SEBRAE, 2016), a empresa de consultoria Euromonitorinforma que o setor de calçados no nosso País quadriplicou na última década o representou um bom desenvolvimento.

\footnotetext{
${ }^{1}$ Graduando em administração, Centro Universitário Doutor Leão Sampaio, Juazeiro do Norte, Ceará, Brasil. Contato: manoel_barros_duarte@hotmail.com

${ }^{2}$ Especialista do Centro Universitário Doutor Leão Sampaio, Juazeiro do Norte, Ceará, Brasil. Contato:manoel@leaosampaio.edu.br
}

335 Id on Line Rev. Mult. Psic. V.12, N. 42, Supl. 1, p. 335-348, 2018 - ISSN 1981-1179

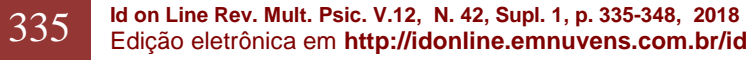


O mercado Brasileiro estava na $14^{\mathrm{a}}$ posição saindo da mesma para $8^{\mathrm{a}}$ posição entre os maiores do mundo em 2013. Nesse mesmo ano o Instituto Brasileiro de Geografia e Estatística (IBGE, 2013) aponta que até novembro a produção tinha crescido 6,6\% como relação ao ano de 2012, já em relação ao varejo calçadista o crescimento foi de $3,3 \%$ em relação ao ano de 2012.

Segundo a empresa Abicalçados (2012), com base em seus dados o Brasil produziu um total de 860 milhões de pares de calçados, entre eles sandálias, chinelos e injetados em geral. Tendo a intenção de construir uma fábrica de calçados em Missão Velha-CE, com o foco em produzir vender na cidade referida e também exportar produtos para outros estados como Pernambuco e Bahia, foi analisado viabilidades e estratégias terão que ser traçadas.

O mercado calçadista da cidade de Juazeiro do Norte, município vizinho, oferece uma oferta muito grande de chinelos, segundo informações do site Diário do Nordeste (2011). Porém a demanda dos estados citado acima é muito maior, mesmo assim esse cenário pode ser bem proveitoso para a implantação da empresa, pois o empreendedorismo será uma tática fundamental, diante da criação de algo novo a partir da identificação de uma oportunidade dedicação, persistência e a ousadia aparecem como atitude importante neste processo para se alcançar os objetivos pretendidos.

Sabendo que cidade de Juazeiro do Norte-CE tem uma grande produção, isso poderia influenciar na introdução da fábrica em Missão Velha-CE, porém a função da fábrica seria produzir e exportar para outras regiões dessa forma a fábrica poderia gerar empregos no setor, e melhorar o desenvolvimento da cidade. Um possível problema seria a dificuldade na aquisição de matéria-prima que está relacionada à distância das cidades vizinhas, já na cidade de Juazeiro do Norte podemos encontrar alguns fornecedores.

O objetivo deste trabalho é analisar a viabilidade de implementação de uma empresa do ramo de calçados na cidade de Missão Velha-CE e seus impactos. Deste modo, e relevante estudar o cenário da região onde a empresa será instalada, verificando a possível demanda e construindo um plano de negócio para a estruturação do mesmo. O propósito deste trabalho é desenvolver um negócio, de forma empreendedora, que terá importância para cidade em estudo no seu desenvolvimento econômico e social, gerando qualidade na economia da cidade e geração de renda, com as oportunidades de empregos.

336 Id on Line Rev. Mult. Psic. V.12, N. 42, Supl. 1, p. 335-348, 2018 - ISSN 1981-1179 Edição eletrônica em http://idonline.emnuvens.com.br/id 


\section{Referencial Teórico}

\section{Planejamento Estratégico}

Com o desenvolvimento do mercado e o crescimento da concorrência é importante analisar e decidir boas estratégias, com o planejamento estratégico às empresas consegue traçar metas em busca de resultados positivos, para Oliveira (2015), o planejamento é o conjunto de ordens e ações com o objetivo de alcançar determinadas posições futuras desejadas. Tende a ficar entre uma mediação sobre o conhecimento e a ação, certa atitude do presente que terá impacto no futuro.

Segundo Nascimento (2006) são muitas as razões que fazem as empresas prestarem atenção em como se desenvolver ao longo prazo, a cada dia que se passa estão dando importância à estratégia empresarial. Dentre elas as causas mais relevantes que podem ser destacadas para o aumento do planejamento estratégico em empresas são: Mudanças rápidas que ocorrem tanto nos ambientes econômico, social, político e tecnológico. Quando não há um planejamento para conduzir o negócio fica um pouco difícil identificar certas necessidades e oportunidades.

Já Maximiano (2006), afirma que o processo de planejamento estratégico atinge a tomada de decisões em relação a qual o padrão de comportamento que a organização planeja seguir, sendo produtos e serviços que pretende oferecer, mercados e clientes que pretende atingir. Seguindo a mesma linha de raciocínio de Maximiano (2006), o autor Kotler (2012) afirma que o planejamento estratégico pode ser visto como o processo gerencial de desenvolver evoluir a empresa e também manter a mesma em uma adequação razoável entre os objetivos e recursos da empresa e as mudanças e oportunidades de mercado.

De acordo com Oliveira (2002), o planejamento estratégico tem finalidade de alcançar os objetivos, metas desejadas e que possam ser feitas de uma maneira correta, usando o mínimo de recursos pela empresa, nela o administrador pode ser responsável pelo conjunto de tomadas de dicções para futuro do negócio, para melhores resultados positivos.

Matos (1999) destaca alguns fatores de importância do planejamento estratégico onde as organizações precisam saber lidar com a incerteza e se adaptarem há um ambiente que pode mudar a todo o momento. Normalmente o planejamento e traçado para um longo prazo, busca 
identificar o problema atual e trazer a solução para o futuro. E importante à participação das pessoas envolvidas no processo de planejamento, pois elas serão responsáveis em fazer com que as coisas aconteçam de melhor forma possível, para chegar ao objetivo final.

Conforme Lacorte (2006) as empresas de pequeno porte surgem de forma coerente em países mais industrializados, onde podem ocorrer criações e gerações de empregos e rendas e ter desenvolvimento na economia.

Müller (2014) afirma que a Matriz SWOT é bastante utilizada na construção das ações estratégicas e também auxilia na sua priorização, são: Forças, Fraquezas, Oportunidades e Ameaças, por meio destas se faz o relacionamento entre os ambientes interno e externo da empresa, resultando na chamada postura estratégica.

\section{Empreendedorismo no Desenvolvimento do Negócio}

De acordo com Chiavenato (2007) o empreendedor é a pessoa que consegue fazer as coisas acontecerem, que tenta ir além das outras mentes, pois é dotada de sensibilidade para os negócios, tem a capacidade de identificar oportunidades. Com esse diferencial transforma ideias em realidade, para benefício próprio e para benefício da comunidade. Por ter criatividade e um alto nível de energia, o empreendedor demonstra imaginação e perseverança, aspectos que, combinados adequadamente, o habilitam a transformar uma ideia simples e mal estruturada em algo concreto e bem-sucedido no mercado será fundamental a introdução desses aspectos no negócio planejado.

Para que um profissional empreendedor venha ser bem-sucedido em seu próprio negócio, o empreendedor tem o desafio de iniciar com um pequeno capital, como no planejamento da fábrica, já existe um pequeno capital. Em um momento do mercado em que mudanças são uma constante, já que estamos em um mundo globalizado onde a tecnologia e a informação exercem grande peso para o mercado.

Segundo Dornelas (2001), para ser um grande empreendedor não basta ter talento, ideia e capital, necessita de determinação dedicação e foco com os objetivos. Já o pensamento de Chiavenato (2007), os empreendedores de sucesso são aqueles que planejam cada passo de seu negócio, que analisam e pesam muito antes de ir adiante. Também afirma que para ser bem- 
sucedido, o empreendedor não deve apenas saber criar seu próprio empreendimento. Precisa também saber gerir seu negócio, para mantê-lo e sustentá-lo em um ciclo de vida prolongado e obter retornos significativos de seus investimentos.

Isso significa administrar, planejar, organizar, dirigir e controlar as atividades relacionadas direta ou indiretamente com o negócio. Ele também explica que existe características básicas para um empreendedor. São elas, a Necessidade de realização: Uma necessidade pessoal, o que o diferencia dos outros, a disposição para assumir riscos: Riscos financeiros e de demais ordens assumidas ao iniciar o próprio negócio. E autoconfiança segurança ao sentir que pode enfrentar os desafios e problemas.

\section{Industria Calçadista}

Segundo Abicalçados (2011), setor mais elevado do estado nordestino é o Ceará, terceiro maior produtor do Brasil, e segundo maior exportador em valores e em maiores partes de calçados representando $45 \%$. O estado apresenta uma grande vantagem logística pelos portos quem possibilita saída rápida para Europa.

Os consumidores estão cada vez mais exigentes e buscando qualidade e um bom preço no produto e comprando cada vez mais, segundo dados da Abicalçados (2017), o aumento de venda pode crescer em quase 4\% no ano de 2018 segundo dados do IBGE, esse aumento foi proporcionado pelas exportações, com isso estamos vivendo uma nova era onde o mercado está crescendo e a população está mais exigente, tendo o poder de escolher entre muitos concorrentes.

Segundo informações do site Diário do Nordeste (2011), o cariri é o maior polo de calçados do nordeste, as indústrias vêm começando como fábricas informalmente em fundo de quintal, só que essas indústrias se fortaleceram e se profissionalizaram e logo estão legais no mercado. O polo calçadista surgiu por volta de 40 anos no cariri, por conta da demanda das sandálias japonesas, logo as empresas tiveram iniciativa de produzir, e com isso a atividade se expandiu e o negócio cresceu.

A fim de entender e buscar melhorias nos negócios as empresas estão inovando e buscando formas e sendo criativas em conquistar o cliente e Segundo Chibas (2000), as pessoas 
confundem inovação e criatividade, porem as duas são bem diferentes onde a criatividade se refere a processos internos, elaboração de ideias e projetos enquanto o termo inovação se refere mais a alguns resultados produtos ou efeitos da criatividade.

\section{Metodologia}

O presente trabalho e de cunho quantitativo, pois segundo Fonseca (2002), amostra geralmente são maiores, feitas com a população. Os resultados são baseados como se constituísse a algo idêntico a toda população onde foi realizada a pesquisa. Concentra-se na objetividade, visto que os resultados podem ser identificados na análise de dados brutos recolhidos na mesma. A pesquisa quantitativa é baseada na matemática para chegar aos resultados e relações entre as variáveis e permite recolher informações do que se poderia conseguir isoladamente.

O levantamento pode ser das seguintes formas: Levantamento de uma amostra ou levantamento de uma população, também designado censo. Sendo assim procura-se analisar a viabilidade da implantação de uma fábrica de calçados, realizando um levantamento com abordagens quantitativas, para maior obtenção de dados, por intermédio de uma pesquisa de opinião. A cidade de missão velha tem uma população de 34.258 mil habitantes confirmadas pelo último censo (IBGE). A pesquisa aconteceu no centro na Rua Coronel Jose Dantas, onde foram abordados adultos do gênero masculino e feminino. Aplicou-se 251 questionários para coleta de dados.

O presente estudo trata-se de um plano de negócio, que tem como cenário de pesquisa do município de Missão Velha-CE, considerando o local escolhido para a implantação do empreendimento. O instrumento utilizado foi o Google Forms questionários. Os dados colhidos foram tabulados e posteriormente analisados, buscando o entendimento do público-alvo, através do Excel. 


\section{Análise e Discussão os Resultados}

O levantamento de dados foi realizado na cidade de Missão Velha-CE com 251 pessoas, foram formuladas 10 perguntas no intuído de saber o perfil do consumidor e como o mesmo escolhe seus calçados. Para cada gráfico segue uma breve análise dos dados indicador que gerou uma nota final. A seguir os gráficos indicarão os resultados.

\section{Gráfico 01: Gênero.}

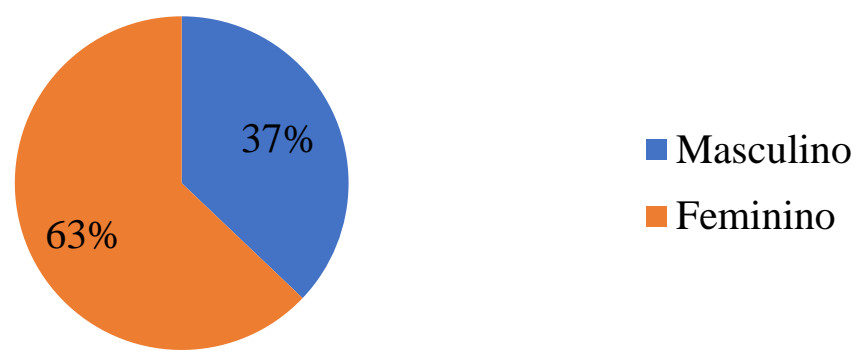

Fonte: Dados da Pesquisa 2018

Conforme apresentado no gráfico 01,158 pessoas eram do gênero feminino com 62,9\% e 93 pessoas do gênero masculino, resultando em 37,1\%. Com esses resultados indicam que a maioria era do gênero feminino, julgando que o fluxo de pessoas na Avenida Coronel José Dantas foi de jovens e mulheres.

Gráfico 02: Faixa Etária.

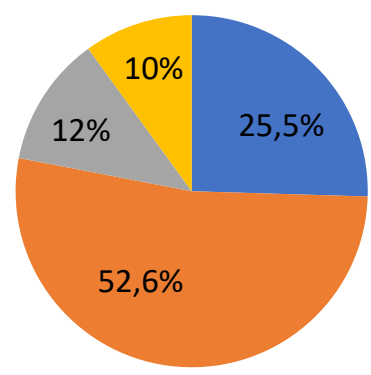

$$
\begin{aligned}
& \text { Entre } 15 \text { e } 18 \\
& \text { entre } 19 \text { e } 25 \\
& \text { entre } 26 \text { e } 36 \\
& \text { acima de } 36
\end{aligned}
$$

Fonte: Dados da Pesquisa 2018. 
De acordo com a pesquisa 132 pessoas estão entre a faixa etária entre 19 aos 25 anos resultando em um percentual de 52,6\% como mostra no gráfico 02 . E 64 pessoas entrevistadas se enquadram na faixa etária de 15 aos 18 anos totalizando um percentual de 25,6\%. Já as pessoas com a faixa etária de 26 aos 36 anos somam 30 participantes, com um percentual de 12\%. E 25 pessoas se enquadraram acima de 36 anos com um total de $10 \%$.

Com esses dados concluísse que a maioria das pessoas entrevistadas tem entre 19 a 25 anos, essa parcela que e caracterizada pelos jovens ocorreu devido a esse público enquadra-se em um século mais moderno e muito mais consumista. O fluxo de jovens na cidade de Missão Velha era muito grande, por esse motivo o gráfico 02 apontou um índice maior entre os jovens.

Gráfico 03: Frequência que Compram Calçados.

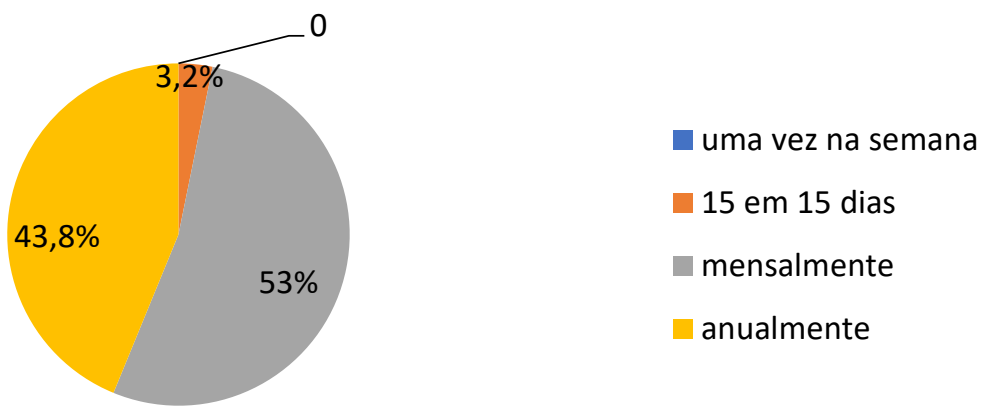

Fonte: Dados da Pesquisa 2018.

Foi analisado que a maioria das pessoas opta em comprar calçados mensalmente, considerando o total de 133 pessoas, representado por um percentual de 53\%, representado no gráfico 03. Seguindo com 110 pessoas que preferem comprar calçados anualmente, representado em $43,8 \%$.

Seguindo por 8 pessoas que preferem comprar calçados de 15 em 15 dias, apontadas em um percentual de 3,2\%. Ninguém optou em comprar calçados semanalmente. Com esses dados conclui-se que a maioria das pessoas compra calçada todos os meses. Sendo ponto favorável para a instalação do referido negócio atacadista. 
Gráfico 04: Motivação na Hora de Comprar Calçados.

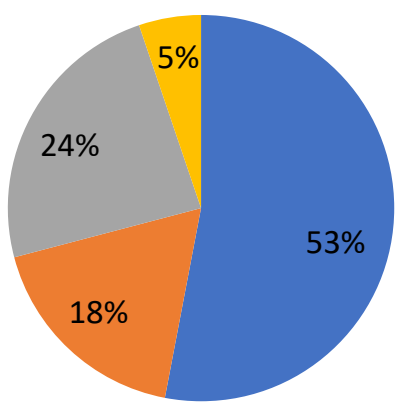

$$
\begin{aligned}
& \text { Qualidade } \\
& \text { Preço } \\
& \text { Moda } \\
& \text { outro }
\end{aligned}
$$

Fonte: Dados da Pesquisa 2018

A pesquisa relatou que as pessoas preferiram a qualidade na hora de escolher calçadas, visto que 133 pessoas totalizando um percentual de 53\% afirmam esta opção. Segundo item que as pessoas escolheram foi moda, atualizações e tendências do mercado, onde 60 pessoas se identificaram, em um percentual de $23,9 \%$. Já o preço foram apenas 45 pessoas, resumindo em um percentual de $17,9 \%$.

Para Chiavenato (2007) o empreendedor deve ter visão e pensar fora da caixa, o negócio terá que ser inovador proporcionar qualidade e um preço atraente, onde a motivação também será fundamental. Dessa forma conclui-se que o cliente na hora de escolher os seus calçados aprecia a qualidade do produto, seguindo moda e o preço.

\title{
Gráfico 05: Renda Mensal.
}

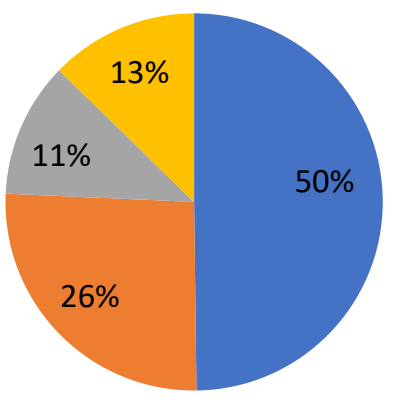

\author{
Até um salario minimo \\ Entre um e dois salário \\ mínimos \\ Entre dois e três salários \\ minimos \\ Acima de três
}

Fonte: Dados da Pesquisa 2018 
Analisando o exibido no gráfico 05, percebe-se que 125 das pessoas da pesquisa têm uma renda mensal de até um salário mínimo, somando um percentual 49,8\%. É notório que 65 pessoas informaram possuir uma renda mensal entre um e dois salários mínimos totalizando um percentual de $25,9 \%$. Ainda 29 pessoas relataram que tinham uma renda mensal entre dois e três salários mínimos com um percentual de 11,6\%. E apenas 32 pessoas informaram que tinha uma renda mensal acima de três salários mínimos. Com essas informações conclui-se que boa parte das pessoas recebe até um salário mínimo.

Gráfico 06: Gasto com Calçados.

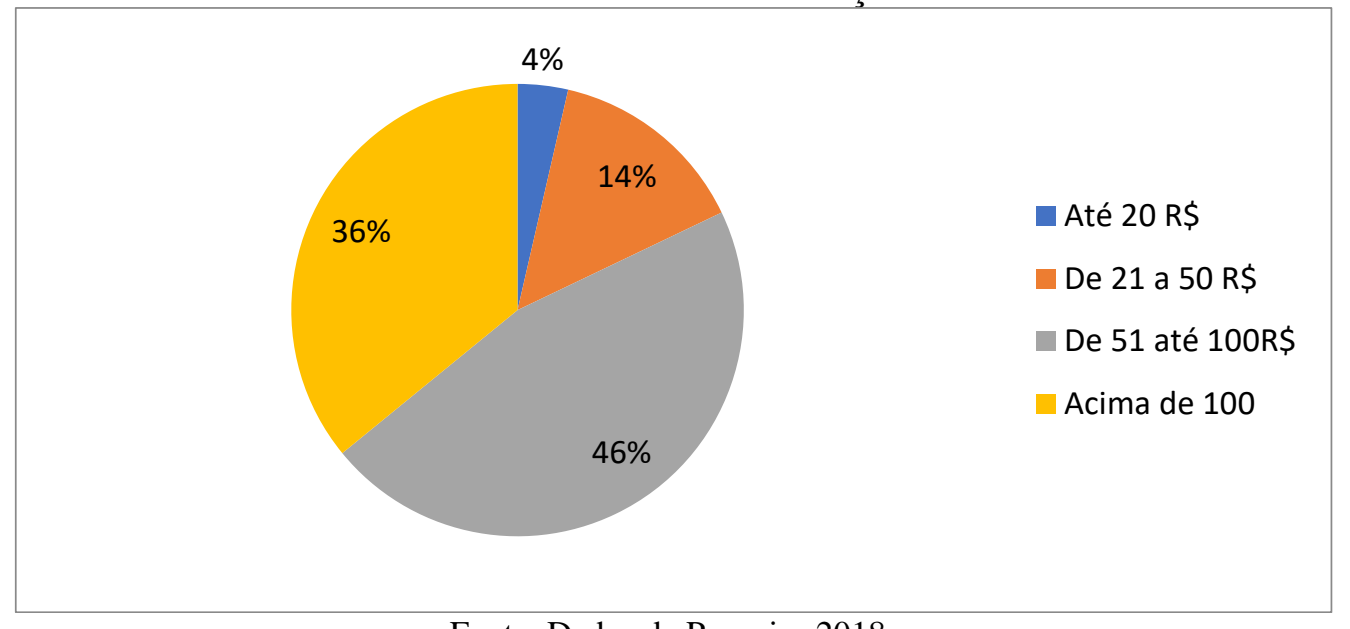

Fonte: Dados da Pesquisa 2018.

De acordo com o gráfico 06, boa parte das pessoas afirma que costumam gastar entre 51 a 100 reais, totalizando um percentual de 46,6\%. E 36\% das pessoas estão dispostas a gastar acima de 100 reais com um calçado.

Com essas informações e com as expostas nos gráficos 04 e 05, pode-se concluir que as pessoas estão dispostas a gastar entre $5 \%$ a $10 \%$ da sua renda mensal na aquisição de calçados, sendo que almejam qualidade no produto e tendências da moda. 
Gráfico 07: Informações Sobre Promoções.

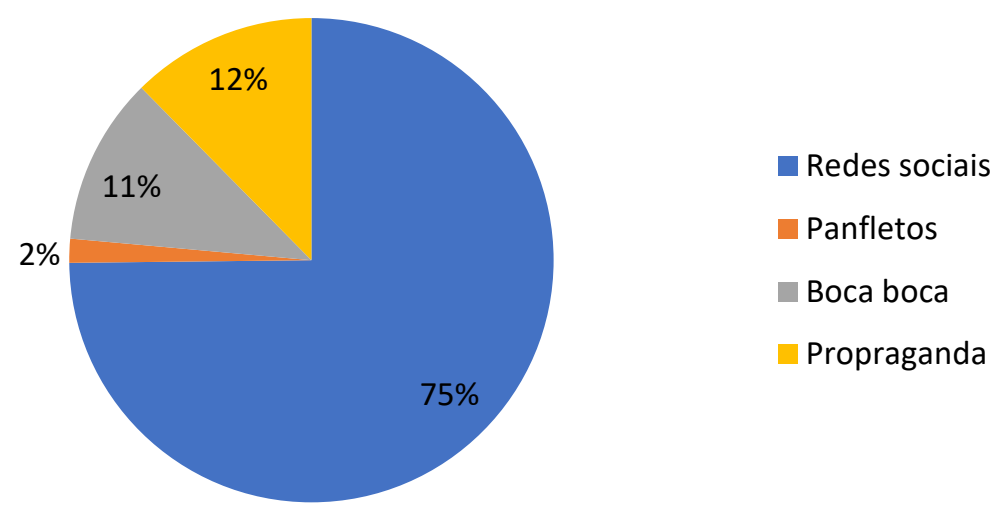

Fonte: Dados da Pesquisa 2018.

O gráfico 07 indentifica como as pessoas da pesquisa tem informaçoes sobre promoções. Como apresentado, 75\% dos participantes (a maioria) pontuam o interrese de saber das promoções por meio de redes sociais.

Gráfico 08: Características na Escolha do Calçado.

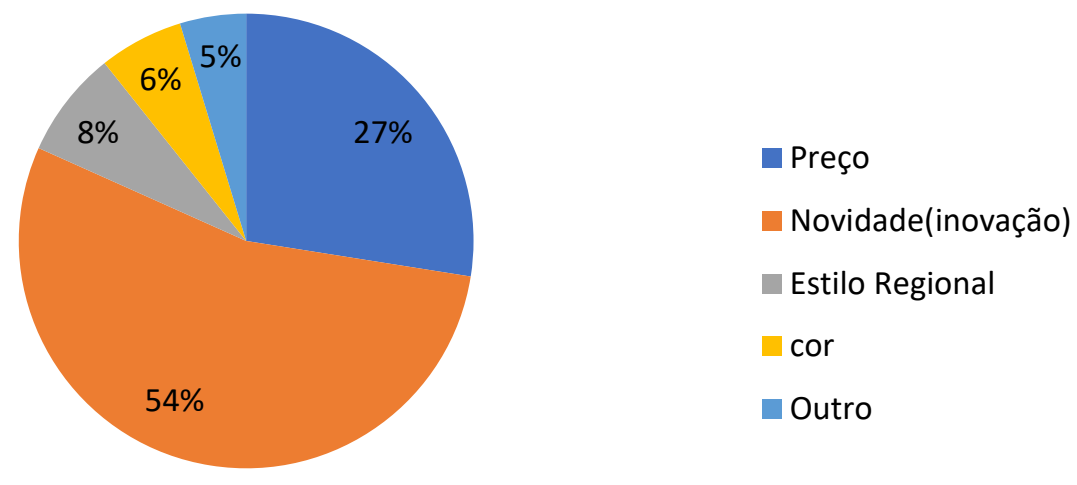

Fonte: Dados da Pesquisa 2018.

Como apresentado no gráfico 08 sobre características da escolha de calçados, 136 pessoas indicaram que preferem novidade e inovação no calçado, com um percentual de 54,2\%, esse índice e superior ao índice do preço, onde 69 pessoas se enquadraram $(27,5 \%)$. 
O gráfico 04 aponta que a maioria das pessoas entrevistadas indicou que preferem a qualidade e depois a moda. Comparando esses resultados, percebe-se que o cliente esta atualizado, em busca de qualidade e novidades nos calçados. Na sequência, estes clientes analisam o preço do calçado.

Gráfico 09: Opinião das Pessoas Sobre a Instalação de uma Fábrica de Calçados na Cidade de Missão Velha-CE.

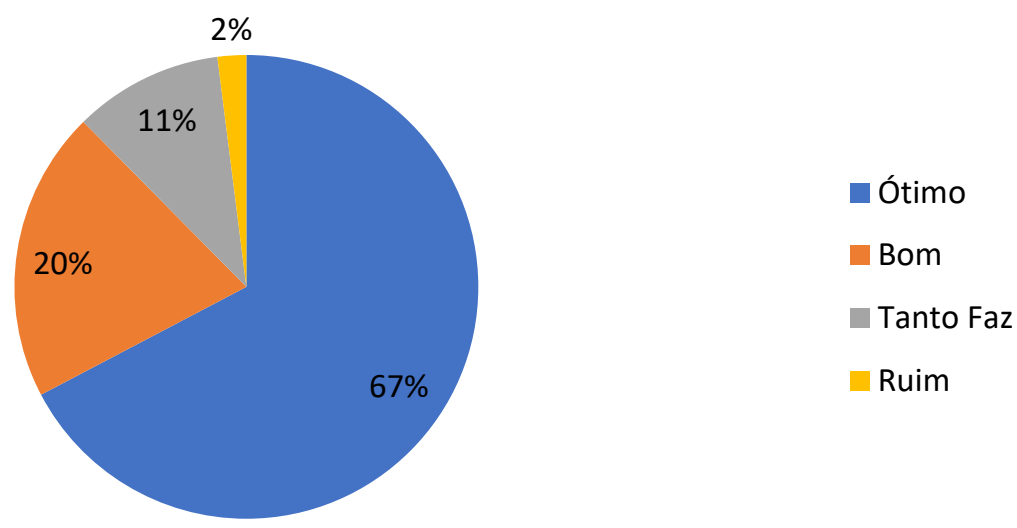

Fonte: Dados da Pesquisa 2018.

Com base no exposto do gráfico 09, a aceitação da população foi positiva, pontuando que 169 pessoas responderam a opção "ótimo", resultando em um total de 67,3\%. Apenas 51 pessoas responderam "bom", resultando em um percentual de 20,3\%. Com isso, pode-se afirmar que os participantes da pesquisa aceitam a instalação da fábrica de calçados.

Gráfico 10: Preferência se Soubesse que o Calçado é Produzido na Cidade de Missão Velha$\mathrm{CE}$ e que Ajuda um Projeto Social?

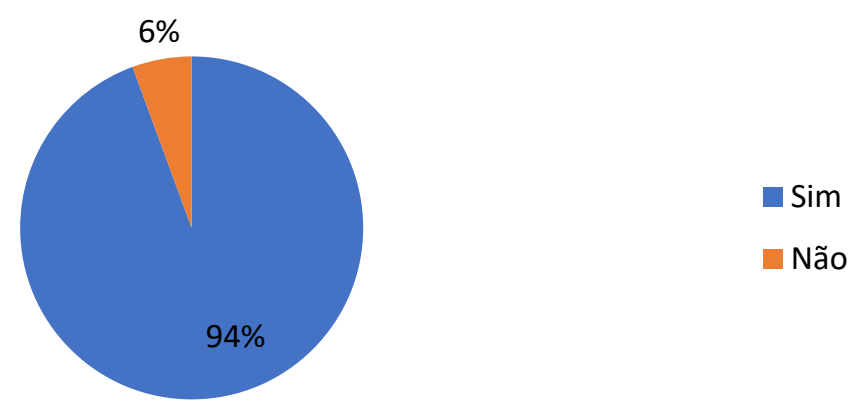

Fonte: Dados da Pesquisa 2018. 
Analisando o gráfico 10, nota-se que $94 \%$ dos participantes da pesquisa pontuam que "sim", daria a preferência na hora de comprar um calçado produzido na cidade em questão, para a implantação da fábrica. Apenas 6\% afirmaram que "não", mesmo a fábrica, quando instalada, auxilie/ajude um projeto social.

\section{Considerações Finais}

Esta pesquisa teve finalidade de analisar a viabilidade de uma fábrica de calçados. No ato foram relatadas técnicas em que o empreendedor necessita ter para um bom desenvolvimento do negócio, usando de um planejamento estratégico para o desenvolvimento do mesmo, como exemplo.

A aceitação do público foi positiva como mostra na análise de resultados. É perceptível que os futuros consumidores almejam nos produtos que serão ofertados, qualidade, moda, tendências, novidades e bons preços nos calçados. Verificando a parte financeira, o investimento teve um total de 71.339,00 reais, incluindo custos variáveis, custos fixos e maquinário, tendo uma receita total de 40.000,00 reais ao mês, com lucratividade de $11.000,00$ reais.

Analisando todos os dados da pesquisa de opinião pública, pode-se concluir que é viável a instalação de uma fábrica de calçados na cidade Missão Velha-CE, com uma boa aceitação da população e uma lucratividade razoável. O negócio tem uma probabilidade alta de ir adiante, mediante a confecção de um planejamento estratégico.

\section{Referências}

ABICALÇADOS. Disponível em: <http://www.abicalcados.com.br/noticia/para-calcadistas-ano-de-2018deve-consolidar-recuperacao>. Acesso em: 02 set. 2018.

CHIAVENATO, Idalberto: Empreendedorismo: Dando asas ao espírito empreendedor. 2. ed. São Paulo: Saraiva, 2007.

CHIBÁS, Ortiz, Felipe. Barreiras à Comunicação e Criatividade Organizacional: Um estudo em hotéis brasileiros e cubanos. São Paulo, 2000. Dissertação [Mestrado] - Programa Pós-Graduação em Integração da América Latina (PROLAM), Universidade de São Paulo. 
DIARIO DO NORDESTE: 2011 disponível em: $<$ http://diariodonordeste.verdesmares.com.br/editorias/negocios/cariri-e-o-maior-polo-calcadista-donordeste-1.315364>. Acesso em: 15 set. 2018.

DORNELAS, J. C. A. Empreendedorismo: transformando ideias em negócios. 5 ed. Rio de Janeiro: Campus, 2001.

FONSECA, J. J. S. Metodologia da pesquisa científica. Fortaleza: UEC, 2002.

KOTLER, P. Administração de marketing. 14. ed. São Paulo: Saraiva, 2012.

KOTLER, P. Administração de Marketing: a edição do novo milênio. São Paulo: Prentice Hall, 2000.

Administração de Marketing. 12 ed. São Paulo: Pearson Prentice hall, 2006.

LACORTE, E. A microempresa e a empresa de pequeno porte no Direito Brasileiro. Anais do II Congresso de Direito e Administração da UNESP. Franca, SP. Ago. 2006.

LAMBIN, J. J. Marketing Estratégico. Lisboa: McGraw Hill, 2000.

MATOS, F. G. Visão e Ação Estratégica. São Paulo: Makron Books, 1999.

MAXIMIANO, A. C. A. Introdução à administração. 6. ed. São Paulo: Atlas, 2006.

MÜLLER, Cláudio José. Planejamento estratégico, indicadores e processos. São Paulo: Atlas, 2014.

NASCIMENTO, D.P. Planejamento estratégico. Consultor em Programas de Qualidade. 2006. Acesso em: 24 set. 2016.

OLIVEIRA, D. P. R. Planejamento estratégico: conceitos, metodologias e práticas. $18^{a}$ edição. SP; ATLAS, 2002.

2009.

Planejamento estratégico: conceitos, metodologia e prática. 26 ed. São Paulo: Atlas,

Atlas - 2015 .

Planejamento Estratégico: Conceitos, Metodologia e Práticas. 33. Ed. São Paulo -

SEBRAE. disponível em: <http://www.sebraemercados.com.br/panorama-do-setor-de-calcados-no-brasil/>. Acesso em: 22 ago. 2018.

\section{Como citar este artigo (Formato ABNT):}

DUARTE, Manoel Barros; COSTA NETO, Manoel Leal. Viabilidade para Criação de uma Fábrica de Calçados em Missão Velha-CE. Id on Line Rev.Mult. Psic., 2018, vol.12, n.42, Supl. 1, p. 335-348. ISSN: 1981-1179.

Recebido: 06/11/2018;

Aceito: 07/11/2018. 